
$\therefore$

\section{PROCESSING AND CHARACTERIZATION \\ OF NBS STANDARD POLYETHYLENE \\ FOR USE AS A NEGATIVE CONTROL \\ MATERIAL}

Anthony J. Bur

Dental and Medical Materials Section

Polymers Division

Institute for Materials Research

National Bureau of Standards

Washington, D.C. 20234

Final Report for Period

September 1, 1976 thru August 31, 1977

November 1977

Issued January 1978

Report of work done under contract with the Material Science Toxicology Laboratories, University of Tennessee.

Prepared for

Material Science Toxicology Laboratories

University of Tennessee

Memphis, Tennessee 38163

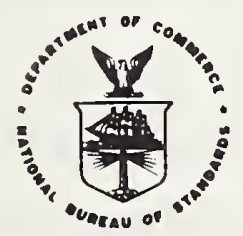

U.S. DEPARTMENT OF COMMERCE, Juanita M. Kreps, Secretary

Dr. Sidney Harman, Under Secretary

Jordan J. Baruch. Assistant Secretary for Science and Technology

NATIONAL BUREAU OF STANDARDS. Ernest Ambler, Acting Director 


\section{;}


The continuing development of new polymeric materials with wide ranging physical properties gives the biomedical engineer extensive latitude in design and application of these materials. One crucial criterion, which these materials must satisfy, is biocompatibility with cardio-vascular and/or intramuscular tissues. Many polymers, which otherwise have desirable physical properties, are eliminated by the biocompatibility tests. These tests are conducted routinely in scores of biomedical laboratories by implantation of polymer test specimens into laboratory animals. ${ }^{1}$ At the present time inter-laboratory comparison of these data is difficult or impossible because control and standardization of the tests on a national scale does not exist. Parameters such as quality, species and diet of the animals are impossible to control and therefore it becomes necessary to "calibrate" each animal during the test. This internal calibration can be accomplished by using a negative control material which is implanted in the animal along with the test specimen. Data is then recorded as tissue reaction to the test specimen relative to its reaction to the control material. If all laboratories use the same negative control; a common reference can be maintained and interlaboratory comparison of data becomes possible.

We describe here the participation of NBS in the development of a candidate negative control material. The source of this material is two large batches of polyethylene whose physical properties have been characterized by the NBS Polymers Division. They have been certified by NBS as Standard Reference Materials (SRM) 1475 and 1476. Lists of some of their physical properties are contained in Appendices A and B. The 1475 SRM is a high density, 
highly crystalline, linear polyethylene. The 1476 SRM is a low density, highly branched polyethylene with low crystallinity.

As indicated above and in appendices A and B, "polyethylene" can be made with different physical characteristics. Parameters such as molecular weight, distribution of molecular weight, density, branching and crosslinking can be changed with corresponding changes in physical properties. In addition, each manufactured batch will have its own residual catalyst, trace elements, and anti-oxident additive. Thus, a material designated only as "polyethylene" is far from completely characterized. The manner in which the above parameters effect the biocompatibility is unknown, but it would be prudent to draw negative control specimens from a single uniformly processed batch.

Polyethylene has been widely used as an implant material, particularly for hip and knee prothesis ${ }^{2}, 3$. It is known that tissue reaction to it is minimal. Also, it is being used routinely as a negative control material by biomedical laboratories which have their own in-house standards. The existing situation has resulted in a proliferation of in-house standards and presents a major obstacle to inter-laboratory comparison of data. Should the NBS polyethylene prove to be a suitable negative control, then a single source would be avallable for all biomedical laboratories for some years to come.

\section{EXPERIMENTAL PROCEDURE}

\section{Fabrication of Sheet and Rod Samples}

The 1475 and 1476 SRM materlal was polymerized in the form of small spherical pellets approximately $3.2 \mathrm{~mm}$ in diameter. While these pellets could be used for tissue culture tests, they are not large enough to use as controls for in vivo testing of large components such as orthopedic implants. The 
material was processed into larger sizes by using standard extrusion and compression molding equipment. Typically, this equipment dictates that the shape of the product be either a rod or sheet. It was decided that suitable dimensions for laboratory work would be rods, $1.59 \mathrm{~mm}$ (1/16") diameter x $15 \mathrm{~cm}$ length and sheets, $16.5 \mathrm{~cm}$ square $\mathrm{x} 0.5 \mathrm{~mm}$ thick. This fabrication was carried out at Drexel University, Philadelphia, PA because their materials laboratory has the equipment to work with relatively small quantities (10-20 kg) of polyethylene and because they could fabricate both rods and sheets in the same laboratory.

Each sheet was compression molded individually using a molding form which had aluminum faces. In order to avold unnecessary contamination of the sheet surfaces no mold release lubricant was used. The pellets were added to the mold which had been previously heated in a hydraulic press to $175^{\circ} \mathrm{C}$ for the 1476 and to $210^{\circ} \mathrm{C}$ for the 1475 . The 1476 pellets were compressed at $175^{\circ} \mathrm{C}$ under a pressure of $2.41 \times 10^{6} \mathrm{~N} / \mathrm{m}^{2}$ (350 psi) for 5 minutes and then cooled under pressure to room temperature in 10 minutes. The 1475 pellets were compressed at $210^{\circ} \mathrm{C}$ under the same pressure (350 psi) for 2 minutes and then cooled under pressure to room temperature in 10 minutes.

Only the 1476 material was made into rods and this was accomplished using an extruder. With this machine, pellets are screw-fed through a heated channel and through an orifice of $1.59 \mathrm{~mm}\left(1 / 16^{\prime \prime}\right)$ diameter. The temperature of the pre-exit channel as well as the orifice was kept at $150^{\circ} \mathrm{C}$. Immediately after exit from the extruder, the filament was quenched by drawing into a bath of distilled water at room temperature. Having obtained operating temperature and an acceptable draw rate, the extruder was run continuously until $45.7 \mathrm{~m}(150 \mathrm{ft}$ ) of filament or rod were extruded. The rod was then cut into $15 \mathrm{~cm}$ lengths. 
Prior to characterization, loose contaminants on the surface of the samples were removed by washing them in a dilute solution of detergent in distilled water (100 mg per litre). A camel's hair brush was used to wipe the surfaces during washing, after which the samples were thoroughly rinsed with distilled water. No organic solvents were used for cleaning because it is known that such small molecules can diffuse into polymeric solids.

\section{Characterization of the Sheets and Rods}

It was essential that the fabricated samples be monitored because, as candidate negative control materials, uniformity of the samples is needed. Although the pellet material is well-characterized, most of the measurements in Appendices $A$ and $B$ do not apply after the pellets have been processed into sheets and rods. In addition, the surfaces of the sheets and rods, being the interface with the biological tissues, need to be investigated with regard to uniformity and the presence of contaminants.

The surface measurements consisted of attenuated total reflectance (ATR) infra-red absorption, contact angle observations, and secondary ion emission mass spectroscopy (SIMS). The first two methods can be classified as macroscopic investigations because the results are obtained from a relatively large area of the surface. The SIMS measurement is an elemental analysis of a small area of the surface, 200 microns square.

The contact angle measurements were obtained using a Ramé-Hart * contact angle apparatus. This equipment consists of a light source, sample chamber, and microscope mounted in horizontal alignment on an optical bench. Droplets of liquid are placed on the surface by using a microsyringe. The contact angle is measured by rotating the cross hair in the microscope to correspond to the tangent of the angle of contact between liquid and solid. In this case droplets of distilled water were used. 
The ATR infra-red measurements were made using the Perkin-Elmer 337 Infracord which was adapted for ATR measurements with a Wilks ATR lens and mirror system. The infra-red absorptions are measured by observing the infra-red light which has undergone multiple reflections from the surface of the test specimen. This light penetrates only several microns into the sample, so that it is the molecular character of the surface and near surface which determines the IR spectra. The surface area of polyethylene sheets from which the spectra was obtained was $4.5 \mathrm{~cm} \times 3.0 \mathrm{~cm}$. For the rods, the ATR spectra was obtained from 26 sections of rod $4.5 \mathrm{~cm}$ in length which were aligned parallel to one another and pressed against the lens which is used as the reflecting medium.

The SIMS measurements were carried out by the Analytical Chemistry Division at NBS. The instrument is a mass spectrometer which analyzes secondary ions ejected from the sample surface as a result of bombardment with accelerated argon 1ons. The sampling volume is usually several hundred angstroms deep by 200 microns square. Absolute measurements of the concentration of trace, elements are not directly obtainable from the SIMS data. An internal standard, such as a dopant of known concentration, must be incorporated in the sample and all other measurements can be referred to this. For the polyethylene sheet and rod, we did not have the resources to do this so that the results are limited to a qualitative indication of the presence of the observed elements and to a relative comparison of results from different samples.

In addition to the above, several bulk characterizations of the sheet and rod were made. These measurements included density, differential scanning colorimetry (DSC), and infra-red transmission spectra. The density measurements were carried out using a density column which was formulated with distilled water and ethyl alcohol according to the ASTM D1505 procedure ${ }^{6}$. The column was 
calibrated with small glass beads of known density. The DSC was used to qualitatively observe the melting and annealing characteristics of the samples and to assess the uniformity of the material from specimen to specimen. A Perkin Elmer DSC-2 instrument was used over a temperature range from $10^{\circ} \mathrm{C}$ to $150^{\circ} \mathrm{C}$.

\section{RESULTS AND DISCUSSION}

The total number of specimens which were examined for this program was 40 sheets and 150 rods, of which 34 sheets and all 150 rods were processed from the 1476 material. Sheets processed from 1476 material were numbered 76-1, 76-2, etc., thru 76-34. The other six sheets are from the 1475 polyethylene and these are designated as $75 \mathrm{~A}$ and $75 \mathrm{D}$ thru $75 \mathrm{H}$. The 150 rods were considered as parts of a single sample since they were extruded in a single process. These 150 rods are not handled individually, but rather a set of 30 rods was selected at random and these were used in the characterization experiments.

From each sheet, a $1.27 \mathrm{~cm}$ wide strip was cut from two adjacent sides and retained for the characterization measurements. Each large sheet and side strip was used for the contact angle measurements but in order to avoid contamination only the side strip was used in the other experiments. Upon completion of the measurements, the sheet was made available for biocompatibility studies and stored in a paper folder. The side strip, also stored in paper, was retained for additional materials study. Paper was used as a storage medium in order to avoid contamination from small organic molecules which are often present in commercially processed plastic packaging material.

\section{Contact Angle Measurements}

Using distilled water droplets, the contact angle was measured for both surfaces of all 40 sheets. Thirty to forty contact angle measurements were made for each side or a total of 60 to 80 measurements per sheet. The 
Average and standard deviation of the contact angle for each sheet is listed in Table 1. Taking all thirty-four sheets of the 76 series, the average contact angle is $90.8^{\circ} \pm 1.8^{\circ}$. For the six sheets of the 75 series, the combined contact angle is $91.8^{\circ} \pm 1.8^{\circ}$. A value of $94^{\circ}$ for water droplets on polyethylene was obtained by Zisman and coworker ${ }^{4,5}$, but the limit of accuracy and standard deviation of their measurements was not given.

Considering the precision and standard deviations normally encountered in contact angle measurements, it is likely that there is no significant difference between our measurements and those in the literature. The existence of some surface differences can not be ruled out, however. For example, a monolayer film of a metallic oxide would be a high energy surface and would allow the water droplet to spread more than on a polyethylene surface. Also, the differences in surface roughness can influence the contact angle. It must be remembered that these measurements are macroscopic and do not give us information about small amounts of surface contaminants.

For the rods, ten samples were selected at random for the contact angle measurements. These ten samples can be considered as different pieces of a single sample since the rods were extruded in one continuous filament and then cut into $15 \mathrm{~cm}$ lengths. During the measurement the rod was oriented perpendicular to the axis of the microscope light beam. The droplet was placed so that it symmetrically straddled the top of the rod. The angle which was measured was the angle between droplet and rod at the very top of the rod while looking transverse to the axis of the rod. At this point 
the effect of gravity in deforming the droplet is least and comparison with the results from a flat surface are possible. This was tested by measuring the contact angle on a flat sheet and then at the apex after the sheet was bent into a $1 \mathrm{~cm}$ diameter circle. No significant difference was found before and after bending.

The results of the contact angle measurements on the rods are shown in Table II. The numbers are seen to be in agreement with those obtained from the sheets. The average for all the rod data points is $91.1^{\circ} \pm 0.7^{\circ}$. Considering that the estimated uncertainty in each measurement is $\pm 0.5^{\circ}$, this result indicates the presence of macroscopic surface uniformity.

The rod contact angle is reasonably close to the $94^{\circ}$ expected for polyethylene, and the slightly depressed value cannot be attributed to material contamination which has been observed in the SIMS measurement. These results, which are discussed below, show that the rod samples have the highest amount of elemental surface contamination.

$\underline{\text { ATR Infra-Red }}$

The results of a representative ATR scan for the sheets or rods processed from the 1476 material are shown in Figure 1. For sheets processed from the 1475 material, a spectrum is shown in Figure 2. In both cases, the spectra are typical of polyethylene with the only differences occurring in the vicinity of $1350 \mathrm{~cm}^{-1}$. Here, the $\mathrm{CH}_{3}$ end groups, which are more numerous in the branched 1476 polymer than in the linear 1475 polymer, show absorption in Figure 1 but not in Figure 2. At $700 \mathrm{~cm}^{-1}$, the typical crystalline amorphous doublet of polyethylene showed some variation fram sample to sample but this was attributed to a polarization effect associated with this band. During the infra-red scan special attention was paid to the regions where carbonyl groups absorb $\left(1750 \mathrm{~cm}^{-1}\right)$ and to the region $400-800 \mathrm{~cm}^{-1}$ 
where metallic oxides absorb. No evidence of oxidation of any kind, carbonyl or metallic, was found in the infra-red spectra. The observations were uniform and typically polyethylene?

Secondary Ion Mass Spectroscopy (SIMS)

The SIMS measurement is more sensitive to the presence of elemental contaminants than is either the contact angle or infrared measurement. Unfortunately, only qualitative information has been obtained because the calibration procedure is an extensive one requiring the preparation of standard samples. We are, however, able to compare the results from sample to sample and to see differences between pellet, sheet and rod. Analysis was carried out on eight samples, 5 sheets, 2 rods and one pellet.

The results are shown in Figures 3 thru 5, in which typical plots of detector response versus the ratio of mass to charge, M/e, are shown. The simplest spectra belongs to the pellet, which is the unprocessed polyethylene. More complex spectra are seen for the sheet and rod. It is apparent that processing, particularly extrusion, is a source of additional contamination which is not seen in the pellet. In the case of the pellet, it is possible to identify all of the peaks, but for the rod samples the spectra was too complex to identify every peak. It is clear that metallic oxides, Sio and Feo, are present on the surface of the rod. Macroscopically the sheet and rod appear to be the same, but it is obvious from these data that the elemental contamination is quite different.

The data for all eight samples are presented quantitatively in Tables III and IV. The numbers in these Tables are the ratio of ion intensity to the carbon 12 ion intensity. Here carbon is taken as the reference ion because, as an essential element in the polyethylene matrix, its intensity would be a constant for all samples. Note that the numbers can not be related to absolute composition because calibration standards for polyethylene are not aṽailable. 
The SIMS results for the rods were somewhat unexpected because there was no indication of contamination from any of the other measurements. The extrusion apparatus had been thoroughly cleansed prior to processing but no analytical check on the extruded product was made until the SIMS measurement months later.

\section{Density Measurements}

The results of the density measurement for the sheets and for fifteen rod samples are shown in Table $V$. It is noteworthy that all of the sheets of a given series are, within the limits of accuracy of the measurement, identical. This result indicates that the temperature-pressure cycle which was used for the preparation of the sheets was uniformly the same for each sheet. The density of the rods, $0.9210 \pm 0.0003 \mathrm{~g} / \mathrm{cm}^{3}$ was slightly lower than the 76 sheets because the rods are quenched rapidly to room temperature as the material exits from the extruder while the sheet is cooled to room temperature under pressure over a period of 10 minutes. Differential Scanning Calorimetry (DSC)

DSC was carried out on several samples of the 75 and 76 series. Typical heating and cooling cycles for these samples are show in Figures 6 and 7 . For sample 75A, the DSC curves show simple melting and crystallization with a melting temperature of $134^{\circ} \mathrm{C}(407 \mathrm{~K})$. For sample $76-14$, however, the DSC curves are more complicated. On the initial heating run a small transition is observed above room temperature at $47^{\circ} \mathrm{C}$ (320K). On the subsequent heating run, which was started only 20 minutes after the one in Figure 7, this transition was absent. Further investigation, e.g. annealing at $60^{\circ} \mathrm{C}$, demonstrated that the $47^{\circ} \mathrm{C}$ transition was due to the melting out of crystals which were formed during storage at room temperature over a period of several months. The sample is continuously undergoing "annealing" even at this low temperature. This is a very small bulk crystallization which 
probably has 1ittle effect on the surface of the material.

The crystallization run is seen in Fig. 7 (b) where the sample is taken from $430 \mathrm{~K}$ to $300 \mathrm{~K}$. The principle crystallization transition occurs at $103 \mathrm{C}$ $(376 \mathrm{~K})$, and there is a secondary crystallization at $68 \mathrm{C}(341 \mathrm{~K})$. Subsequent cycling at different heating and cooling rates showed that this secondary transition was a true crystallization phenomenon and not a kinetic artifact. This $68 \mathrm{Ctransition}$ is also present in the DSC curves for the 1476 pellet. We speculate that it is due to the crystallization of short side branches in the 76 material. This transition is not observed in sample $75 \mathrm{~A}$ which has very little branching.

\section{CONCLUSIONS}

The macroscopic observations, contact angle, ATR-IR, density and DSC show that, within the precision of these measurements, the sheet and rod samples are uniform. The small difference in density between the sheet and rods of the 76 series, $0.9260 \mathrm{~g} / \mathrm{cm}^{3}$ versus $0.9210 \mathrm{~g} / \mathrm{cm}^{3}$, arises because quenching the extruded rod results in a lower rod density. There is no evidence of macroscopic contamination in the observations.

The SIMS apparatus, as an analytical tool, is far more sensitive than the above experiments. It is possible to trace the contamination which is added to the material during processing from pellet to rod and from pellet to sheet. In spite of this, the SIMS data show that there is a measure of uniformity in the resultant product. It is suggested that the contamination is uniformly imparted to the samples. Of the five sheets, there is a similarity in the relative amounts of and the species of elements which are present. Although the elemental analysis of the rods is significantly different from the sheet, the SIMS results for the two rods are similar. 
The differences in the SIMS analysis of the sheet and rod arise because of the different methods of manufacturing, compression molding for the sheets and extrusion for the rods. For the subsequent bio-compatibility studies, it is important to know that these differences exist so that potential correlations of data can be understood.

Other conclusions come from our experience in dealing with the processing of polyethylene. In this case, two kinds of polyethylene were available, one a high density linear polymer (1475) and the other a branched low density sample (1476). Molding the high density material into uniformly flat samples was difficult because contraction during crystallization caused a visible variation in surface texture. It is not known whether this is harmful in terms of biocompatibility, but there is an obvious difficulty in controlling the macroscopic surface uniformity. On the other hand, molding of the low density 76 series sheets resulted in visible uniformity for the samples.

From a processor's point of view, the biggest difference between compression molding and extrusion is economics. Compression molding requires detailed preparation, and cycling of temperature and pressure, all of which take several hours for each sample. For the rods, however, once the extruder has been flushed and cleaned, the machine can be fed continuously while extruding rods in one long tilament. The efficiency of the extrusion machine makes it a practical method of processing large quantities of material. For laboratory studies involving tissue culture analysis, a large quantity of negative control material is often used and extrusion is the only practical method of processing the material. 
If biocompatibility tests demonstrate the suitability of this material as a negative control, proper attention must be given to methods of processing and the elemental contamination which results. It is apparent from these tests that only a sensitive analytical tool such as SIMS can be used to observe the differences between surfaces of these polyethylene samples.

\section{ACKNOWLEDGEMENTS}

The author wishes to acknowledge the assistance of Prof. Ihab Kamel and Mr. George Halldin at Drexel University, who processed the sheet and rod material in their laboratory. Also, acknowledgements are due to Dr. Dale Newberry of the NBS Analytical Chemistry Division who made the SIMS measurements.

* Certain commercial materials and instruments are identified in this report to adequately specify the experimental procedure. In no instance does such identification imply recommendation or endorsement by the National Bureau of Standards, nor does it imply that the material or instrument identified is necessarily the best available for this purpose 


\section{References}

1. See, for example, J. E. Turner, W. H. Lawrence and J. Autian, J. Biomed. Mat. Res., 1, 39(1973).

2. J. Charnley, Clin. Orthop. Related Res. 72, 7(1970).

3. E. Englebrecht, Excerpta Med. 298, 33(1973).

4. W. A. Zisman in "Contact Angle Wettability and Adhesion", Advances in Chemistry Series No. 43, Publ. by American Chemical Society, Washington, D. C., 1964, p 13 and 149.

5. H. Schonborn in "Encyclopedia of Polymer Science and Technology", Vo1. 13, p 549, J. Wiley and Sons, New York, NY 1970.

6. Annual Book of ASTM Standards, Part 35, p 507, Test D1505, American Soclety for Testing Materials, Philadelphia, PA 1977.

7. M. P. Groenewege, J. Schuyer, J. Smidt and C. A. F. Tuynman in "Crystalline Olefin Polymers", Part I, Edited by R. A. V. Roff and K. W. Doak, Interscience Publ., New York, NY 1965, Chapt 14. 
Table I. Contact Angle for Water Droplets on Polyethylene Sheets.

\begin{tabular}{|c|c|c|c|}
\hline Sample & $\frac{\text { Angle }}{\text { (degrees) }}$ & Samp1e & $\frac{\text { Angle }}{\text { (degrees) }}$ \\
\hline $76-1$ & $90.1 \pm 1.4$ & $76-21$ & $91.7 \pm 2.0$ \\
\hline $76-2$ & $89.9 \pm 1.7$ & $76-22$ & $91.2 \pm 1.5$ \\
\hline $76-3$ & $91.2 \pm 1.2$ & $76-23$ & $92.5 \pm 1.9$ \\
\hline $76-4$ & $90.7 \pm 1.9$ & $76-24$ & $91.9 \pm 2.3$ \\
\hline $76-5$ & $90.4 \pm 1.7$ & $76-25$ & $92.9 \pm 1.5$ \\
\hline 76.6 & $92.3 \pm 1.3$ & $76-26$ & $91.4 \pm 2.1$ \\
\hline 76.7 & $89.9 \pm 2.9$ & $76-27$ & $92.6 \pm 1.7$ \\
\hline $76-8$ & $90.6 \pm 1.8$ & $76-28$ & $92.2 \pm 2.0$ \\
\hline $76-9$ & $91.3 \pm 2.0$ & $76-29$ & $92.0 \pm 1.4$ \\
\hline $76-10$ & $93.0 \pm 1.8$ & $76-30$ & $92.0 \pm 1.1$ \\
\hline $76-11$ & $90.5 \pm 0.8$ & $76-31$ & $92.5 \pm 1.6$ \\
\hline $76-12$ & $90.7 \pm 1.1$ & $76-32$ & $91.2 \pm 1.5$ \\
\hline $76-13$ & $90.4 \pm 1.3$ & $76-33$ & $89.9 \pm 2.4$ \\
\hline $76-14$ & $90.8 \pm 0.9$ & $76-34$ & $92.0 \pm 1.5$ \\
\hline $76-15$ & $91.7 \pm 2.0$ & $75 \mathrm{~A}$ & $90.5 \pm 0.8$ \\
\hline $76-16$ & $89.8 \pm 1.8$ & $75 \mathrm{D}$ & $91.7 \pm 1.8$ \\
\hline $76-17$ & $90.9 \pm 1.8$ & $75 E$ & $91.9 \pm 1.8$ \\
\hline $76-18$ & $92.0 \pm 1.7$ & $75 F$ & $92.3 \pm 1.7$ \\
\hline $76-19$ & $91.2 \pm 2.0$ & $75 G$ & $91.8 \pm 1.8$ \\
\hline $76-20$ & $90.9 \pm 1.0$ & $75 \mathrm{H}$ & $91.5 \pm 1.8$ \\
\hline
\end{tabular}


Table II. Contact Angle for Water Droplets on Polyethylene Rods.

$\begin{array}{cccc}\text { Sample } & \frac{\text { Angle }}{(\text { degrees })} & \text { Sample } & \frac{\text { Angle }}{\text { (degrees) }} \\ 1 & 91.0 \pm 0.6 & 6 & 91.2 \pm 0.7 \\ 2 & 91.1 \pm 0.6 & 7 & 91.0 \pm 0.7 \\ 3 & 91.0 \pm 0.8 & 8 & 91.0 \pm 0.7 \\ 4 & 91.2 \pm 0.5 & 9 & 91.0 \pm 0.6 \\ 5 & 91.3 \pm 0.7 & 10 & 91.0 \pm 0.6\end{array}$


Table III. Normalized Secondary Ion Signals (all signals normalized to ${ }^{12} \mathrm{C}^{+}$)

Sheet Samples

\begin{tabular}{ccccccc} 
Ion & $76-2$ & $76-3$ & $76-4$ & $76-20$ & $75 \mathrm{~A}$ & $\begin{array}{c}\text { Pellet } \\
1476\end{array}$ \\
\hline $\mathrm{H}^{+}$ & 0.25 & 0.50 & 0.77 & 0.73 & 0.26 & 1.5 \\
${ }^{7} \mathrm{Li}^{+}$ & -- & -- & -- & -- & -- & -- \\
$\mathrm{CH}^{+}$ & 0.037 & 0.061 & 0.045 & 0.13 & 0.10 & 0.09 \\
${ }^{14} \mathrm{~N}^{+}$ & 0.030 & 0.020 & 0.033 & 0.05 & 0.018 & 0.031 \\
${ }^{16} \mathrm{O}^{+}$ & 0.033 & 0.019 & 0.044 & 0.022 & 0.024 & 0.010 \\
${ }^{23} \mathrm{Na}^{+}$ & 0.032 & 0.057 & 0.053 & 0.05 & 0.134 & 0.009 \\
${ }^{24} \mathrm{Mg}^{+}$ & 0.055 & 0.102 & 0.153 & 0.1 & 0.166 & 0.026 \\
${ }^{27} \mathrm{Al}^{+}$ & 0.378 & 0.314 & 0.291 & 0.45 & 1.39 & 0.040 \\
${ }^{28} \mathrm{Si}^{+}$ & 0.166 & 0.202 & 0.263 & 0.28 & 0.55 & 0.051 \\
${ }^{39} \mathrm{~K}^{+}$ & -- & -- & -- & 0.038 & 0.044 & -- \\
${ }^{40} \mathrm{Ca}^{+}$ & 0.106 & 0.097 & 0.135 & 0.06 & 0.38 & 0.022 \\
${ }^{48} \mathrm{TI}^{+}$ & -- & -- & -- & -- & 0.038 & -- \\
${ }^{52} \mathrm{Cr}^{+}$ & -- & 0.022 & 0.019 & -- & 0.007 & -- \\
${ }^{56} \mathrm{Fe}^{+}$ & -- & 0.039 & 0.039 & 0.02 & 0.045 & 0.009
\end{tabular}


Table IV. Normalized Secondary Ion Signals

(all signals mormalized to ${ }^{12} \mathrm{C}^{+}$)

\section{Rod Samples}

\begin{tabular}{|c|c|c|c|}
\hline Ion & Rod 1 & Rod 2 & $\begin{array}{c}\text { Pellet } \\
1476\end{array}$ \\
\hline${ }_{\mathrm{H}^{+}}+$ & 1.4 & 0.75 & 1.5 \\
\hline${ }^{7} \mathrm{Li}^{+}$ & - & 0.0053 & - \\
\hline $\mathrm{CH}^{+}$ & 0.25 & 0.23 & 0.09 \\
\hline${ }^{14} \mathrm{~N}^{+}$ & 0.084 & 0.14 & 0.031 \\
\hline $16 \mathrm{O}^{+}$ & 0.12 & 0.23 & 0.010 \\
\hline${ }^{23} \mathrm{Na}^{+}$ & 0.19 & 0.38 & 0.0088 \\
\hline${ }^{24} \mathrm{Mg}+$ & 0.39 & 0.65 & 0.026 \\
\hline${ }^{27} \mathrm{Al}^{+}$ & 0.35 & 0.88 & 0.040 \\
\hline${ }^{28} \mathrm{Si}^{+}$ & 1.8 & 1.28 & 0.051 \\
\hline $39_{K^{+}}+$ & 0.061 & 0.25 & - \\
\hline${ }^{40} \mathrm{Ca}^{+}$ & 0.24 & 0.56 & 0.022 \\
\hline${ }^{52} \mathrm{Cr}^{+}$ & 0.0048 & 0.017 & - \\
\hline${ }^{56} \mathrm{Fe}^{+}$ & 0.23 & 0.21 & 0.0089 \\
\hline
\end{tabular}


Table V. Density of Polyethylene Sheets and Rods

\begin{tabular}{cc} 
Sample & $\frac{\rho}{\mathrm{g} / \mathrm{cm}^{3}}$ \\
\hline $75 \mathrm{~A}, 75 \mathrm{D}$ thru $75 \mathrm{H}$ & $0.9632 \pm 0.0005$ \\
$76-1$ thru $76-34$ & $0.9260 \pm 0.0005$ \\
76 ROD (16 pieces) & $0.9210 \pm 0.0003$
\end{tabular}




\section{Figure Captions}

Figure 1. Attenuated Total Reflectance Infra Red Spectra for Sample 76-10. This spectra was typical for all sheets and rods of the 76 series.

Figure 2. Attenuated Total Reflectance Infra Red Spectra for sample 75A. This spectra was typical for all sheets of the 75 series.

Figure 3. Trace of the SIMS data for a pellet of the NBS 1476 standard reference polyethylene material.

Figure 4. Trace of the SIMS data for the compression molded sheet sample 76-20.

Figure 5. Trace of the SIMS data for a piece of extruded 76 rod.

Figure 6. (a) DSC melting curve for sample 75A;

(b) DSC crystallization curve for sample 75A.

Figure 7. (a) DSC melting curve for sample 76-14;

(b) DSC crystallization curve for sample 76-14. 


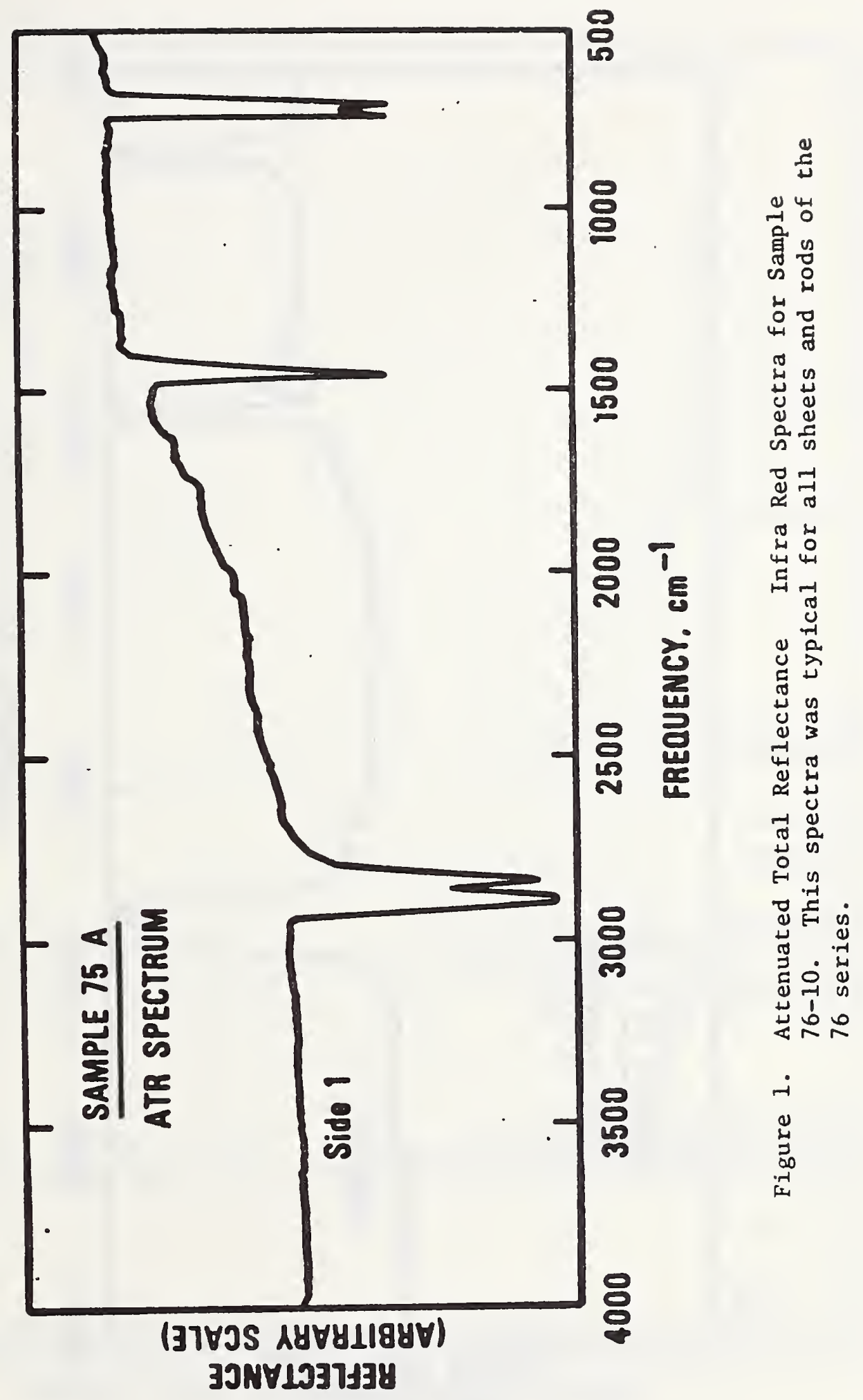




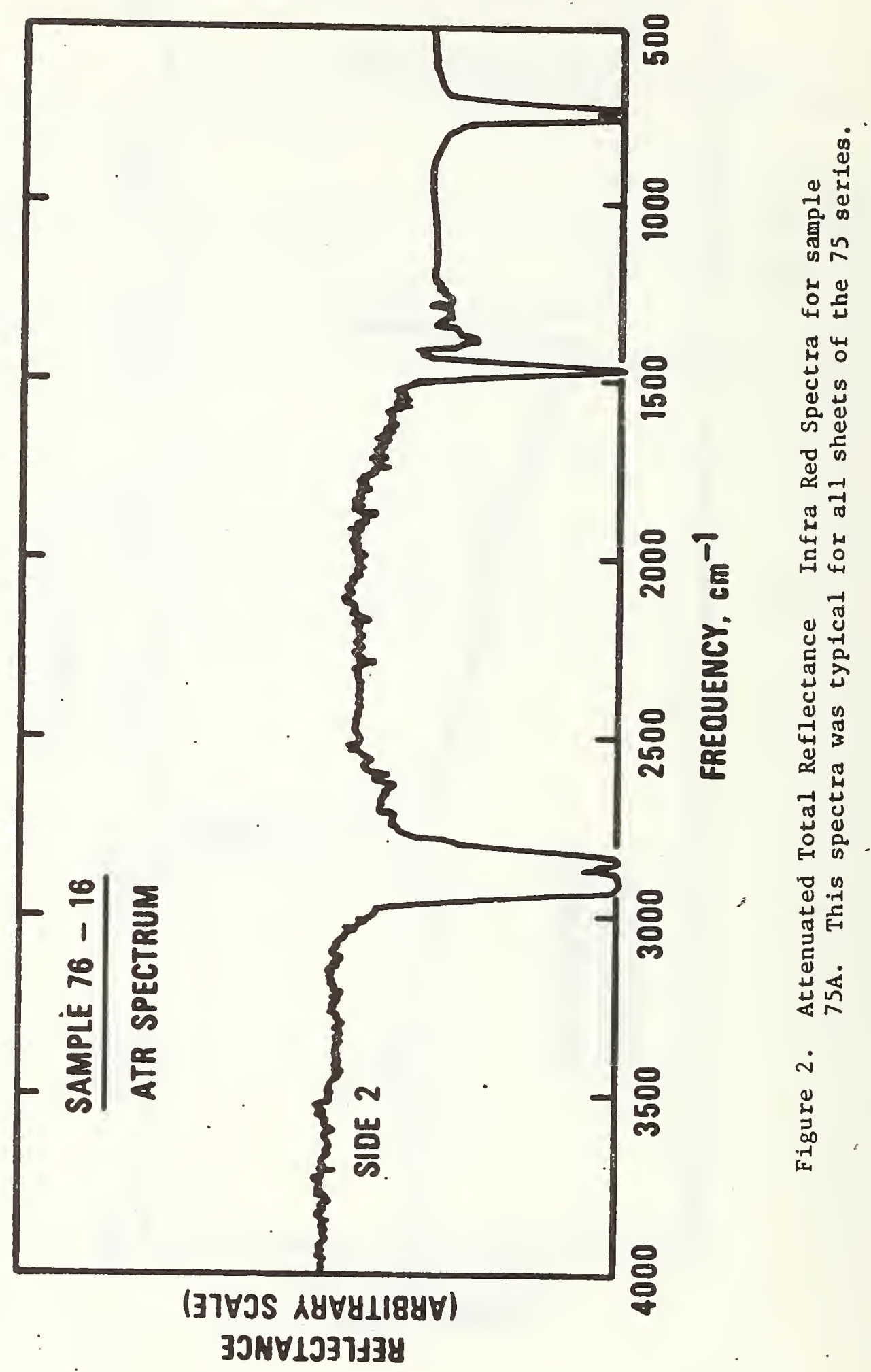




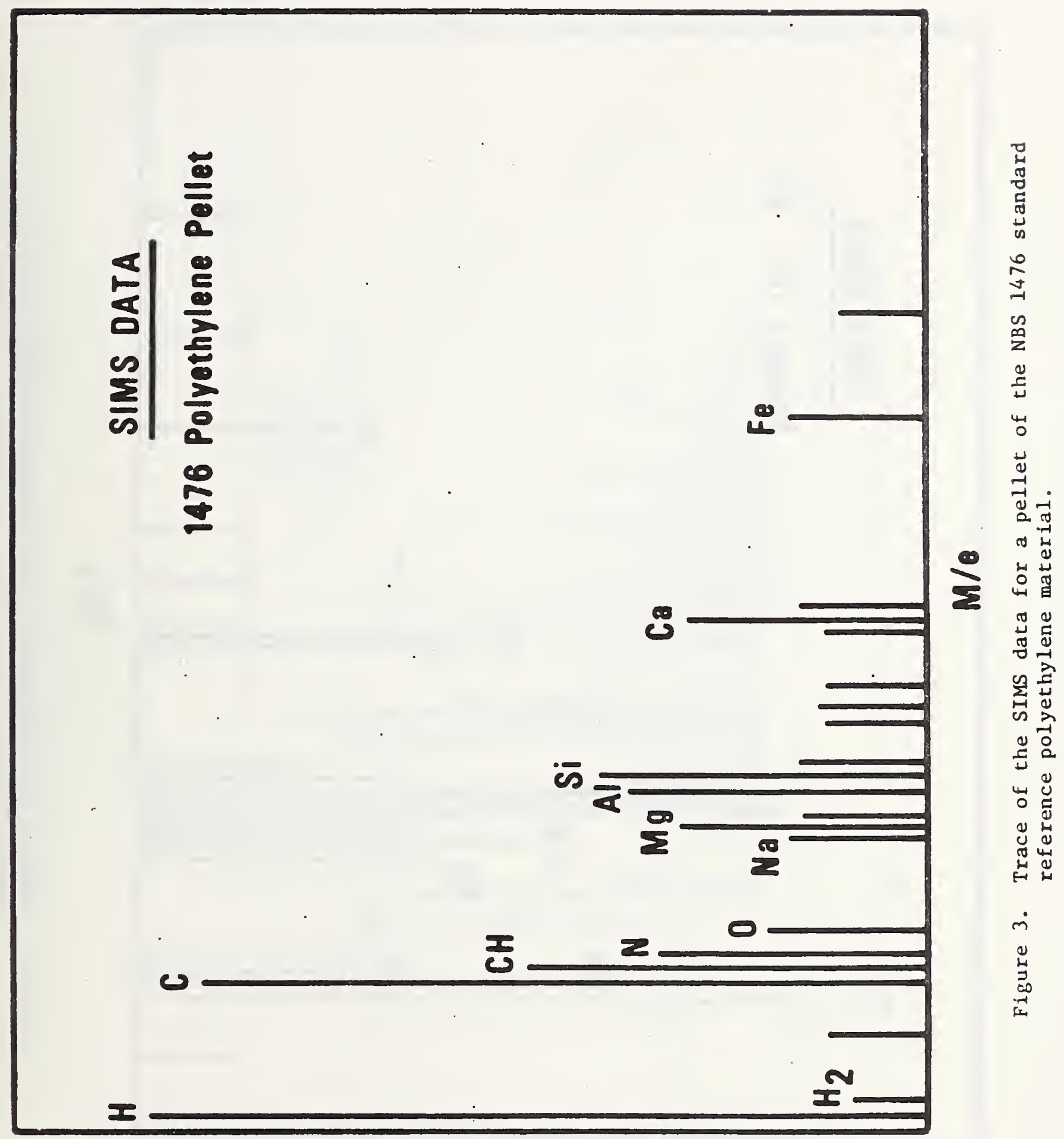

(OIEJS BOI) JSNOdS3Y YO 193130 


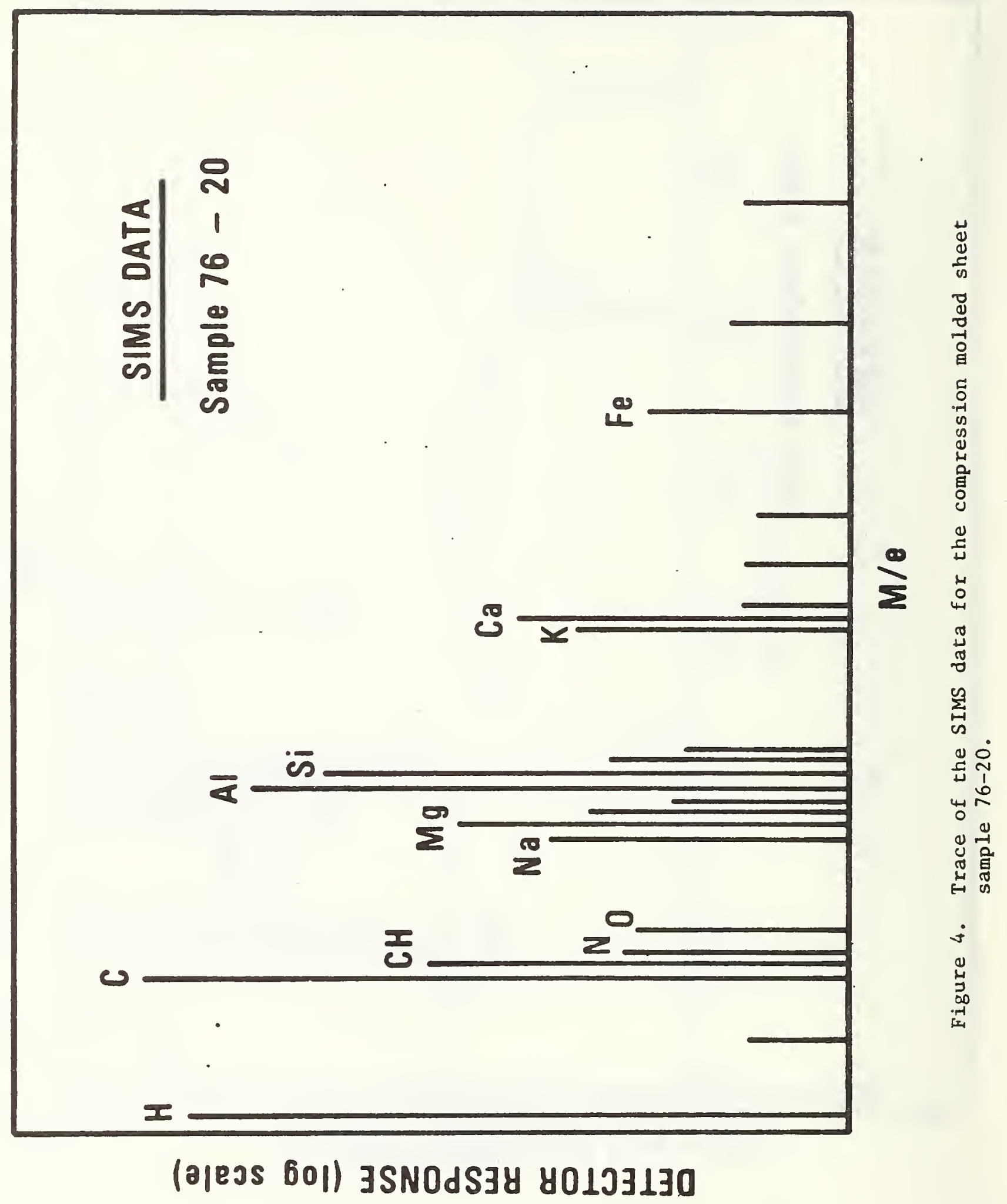




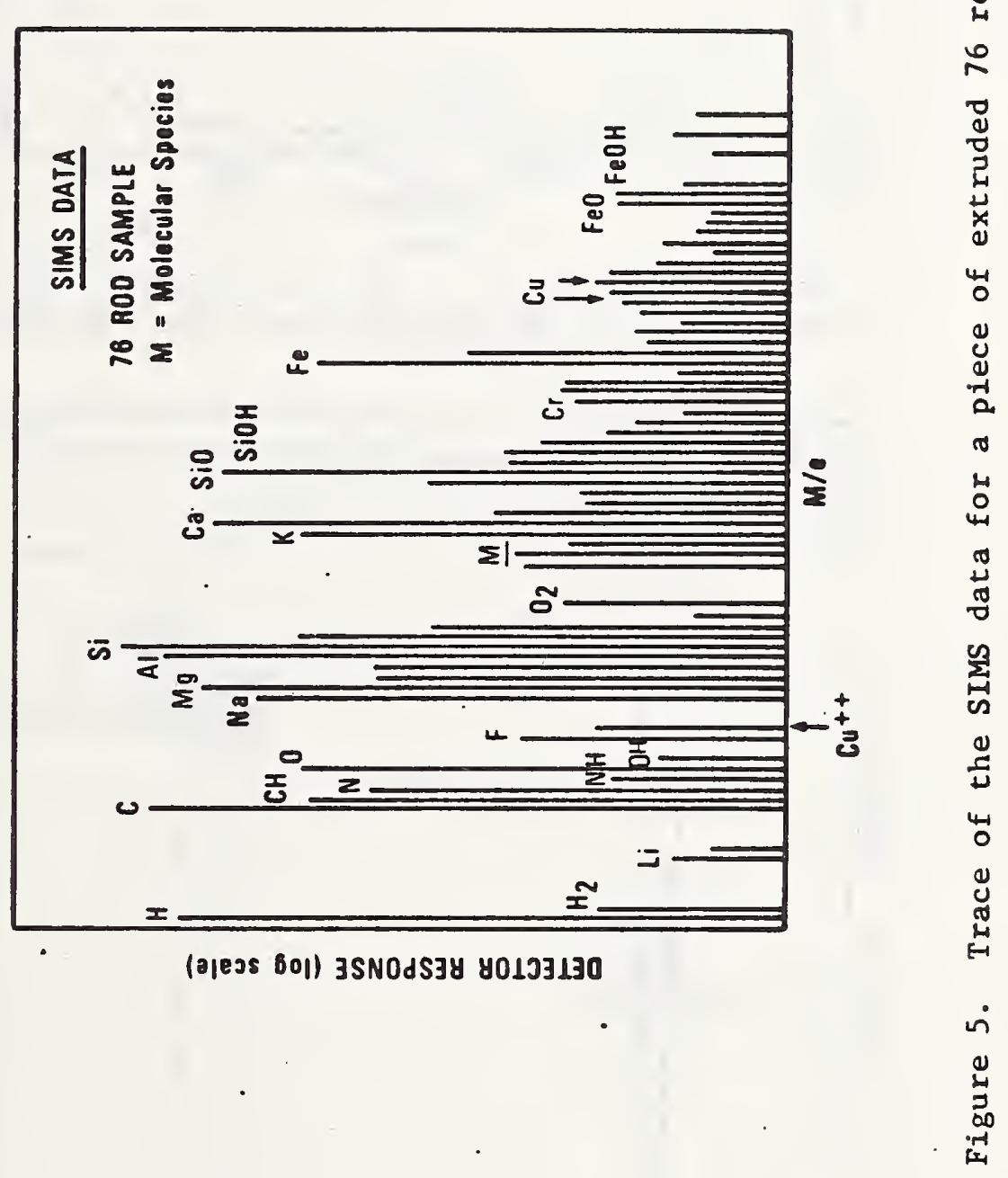




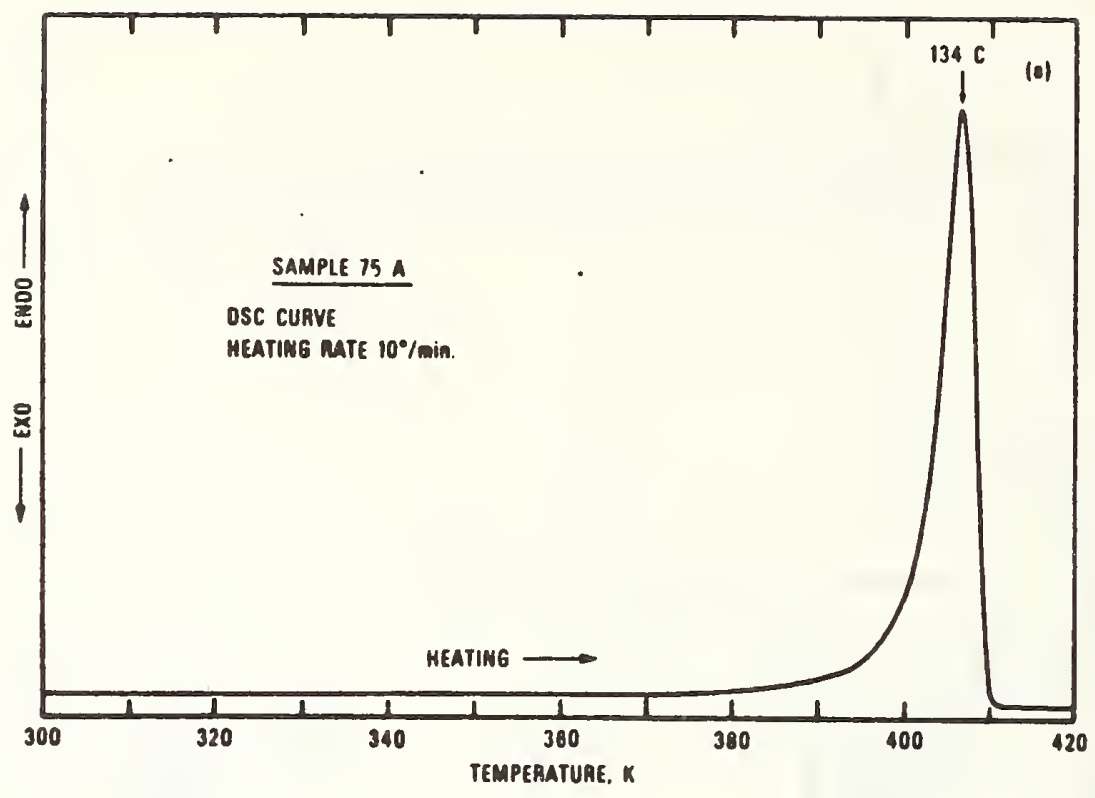

Figure 6. (a) DSC melting curve for sample 75A;

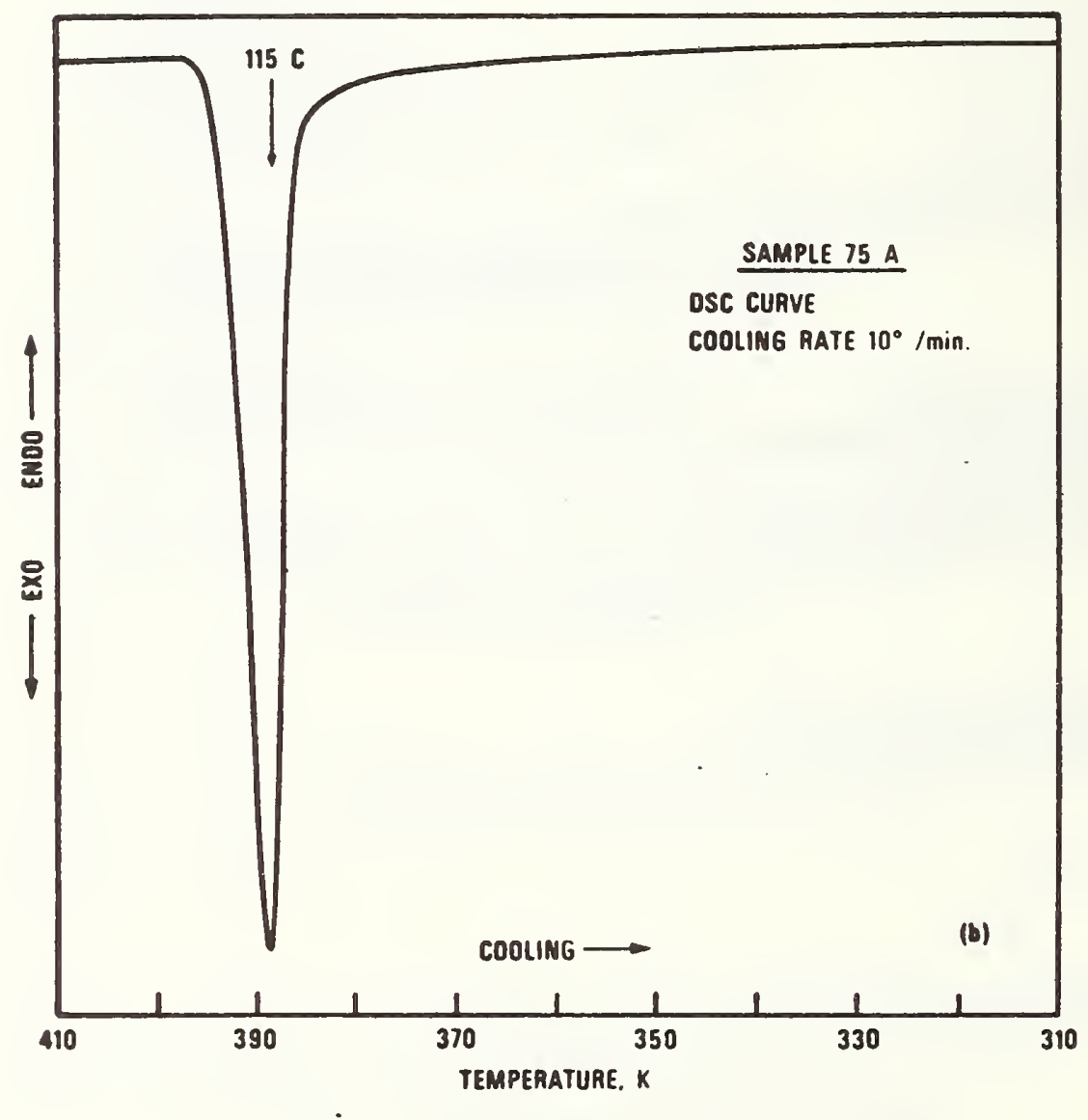

Figure 6. (b) DSC crystallization curve for sample 75A. 


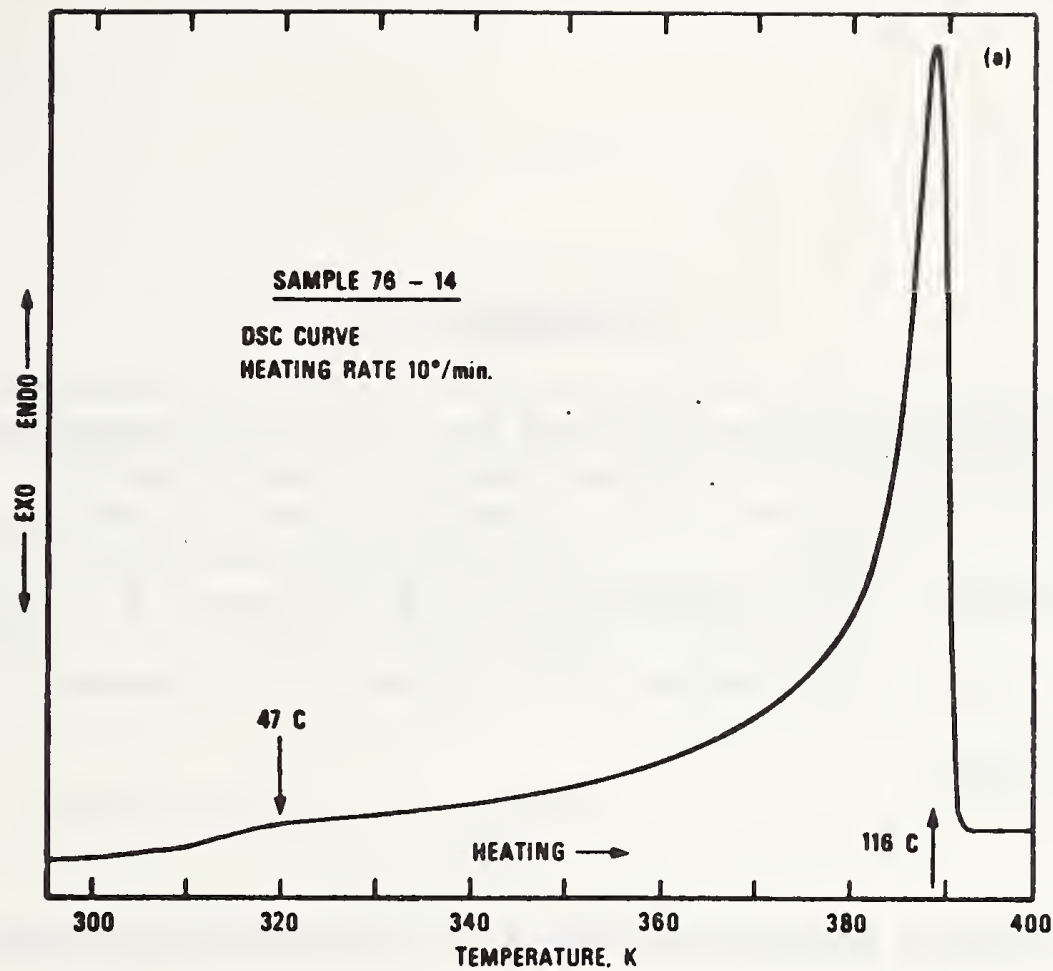

Figure 7. (a) DSC melting curve for sample 76-14;

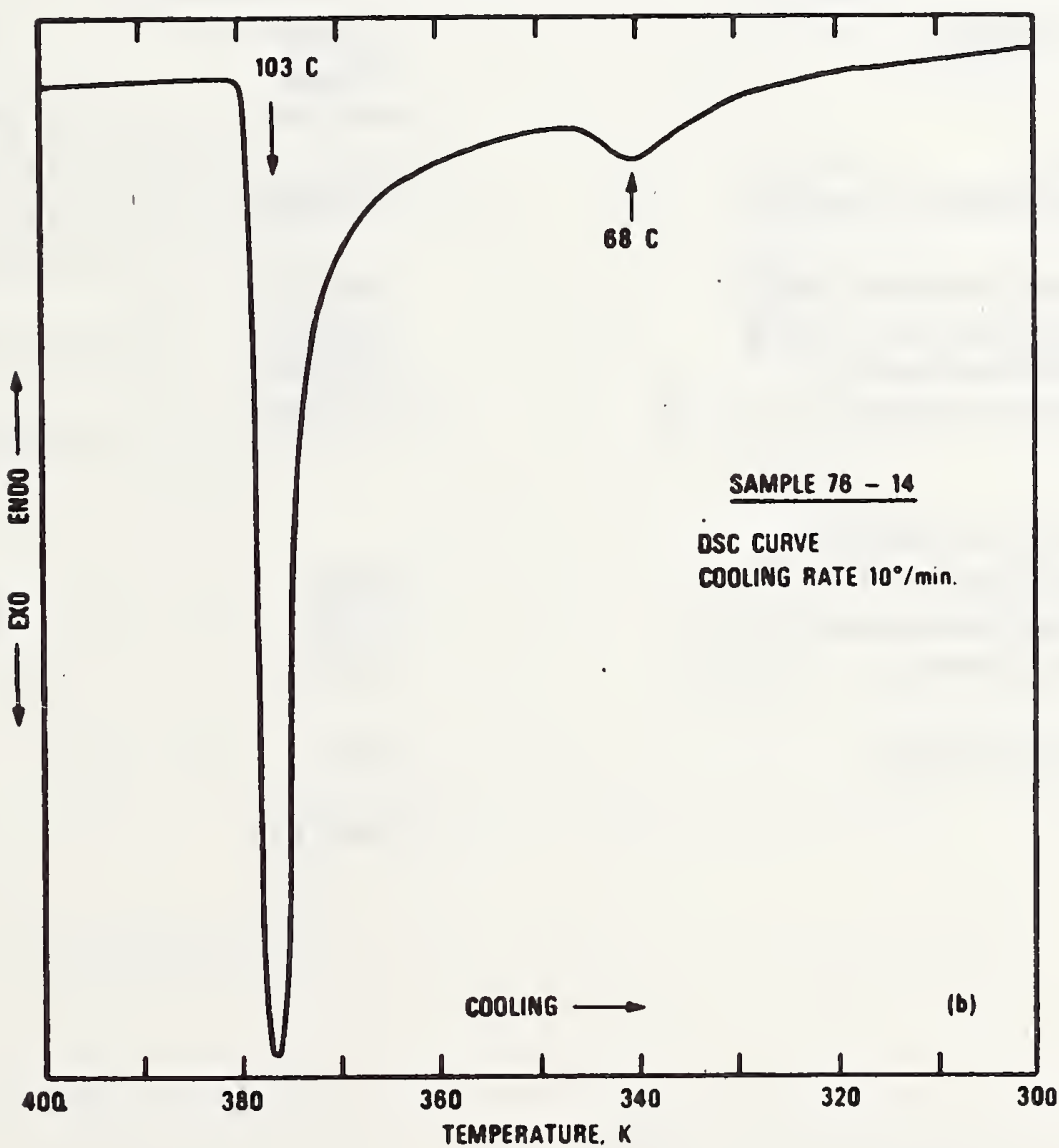

Figure 7. (b) DSC crystallization curve for sample 76-14. 


\section{Appendix A}

The following data was obtained for the 1475 polyethylene pellet material. The experiments and data analysis were carried out by NBS Polymers Division Staff consisting of C. A. J. Hoeve, H. L. Wagner, J. E. Brown, R. G. Christensen, L. J. Frolen, J. R. Maurey, G. S. Ross, and P. H. Verdier.

\section{Standard Reference Material 1475 Linear Polyethylene}

\section{Quantity}

Molecular Weight

Weight-average molecular weight

Number-average molecular weight

Weight-average molecular weight

$\mathrm{Z}$-average molecular weight

Ratio of molecular weights $M_{2}: M_{w}: M_{n}$

Limiting Viscosity Number (dl/g)

In 1-chloronaphthalene at $1.300^{\circ} \mathrm{C}$;

In $1,2,4$-trichlorobenzene at $130^{\circ} \mathrm{C}$

In decahydronaphthalene at $130^{\circ} \mathrm{C}$

Nell-Flow Rate $(\mathrm{g} / 10 \mathrm{~min})$

Density $\left(\mathrm{g} / \mathrm{cm}^{3}\right)$
Average

Values

52,000

18,310

53,070

138,000

$7.54: 2.90: 1$
Estimated Standard Deviation of A verage

2,000

360

620

3,700
0.890

1.010

1.180

2.07

0.97844
0.0032

.0086

.0032

.0062

.00004 


\section{Appendix B}

The following data was obtained for the 1476 polyethylene pellet material. The experiments and data analysis were carried out by NBS Polymers Division Staff consisting of C. A. J. Hoeve, H. L. Wagner, J. E. Brown, R. G. Christiensen, and J. R. Maurey.

\section{Standard Reference Material 1476 Branched Polyethylene}

\section{Quantity}

Limiting Viscosity . Vumber ( $\mathrm{dl} / \mathrm{g})$

In 1-chloronaphthalene at $130^{\circ} \%$

In 1,2,4-trichlorohenzene at $1: 30^{\circ} \mathrm{C}^{\circ}$ In decalina at $130{ }^{\circ} \mathrm{C}$

Melt Index (g/10 min)

Density $\left(\mathrm{g} / \mathrm{cm}^{3}\right)$ at $23^{\circ} \mathrm{C}$
Average

Values

0.8132

.9024

1.042

1.19

(0.9312
Fstimate

of

Precision

$0.11(1.333$

.(1)131

.(1)(1).2

.010

.0000 
NBS-114A (REV. 7-73)

\begin{tabular}{|c|c|c|c|}
\hline $\begin{array}{l}\text { U.S. DEPT. OF COMM. } \\
\text { BIBLIOGRAPHIC DATA } \\
\text { SHEET }\end{array}$ & $\begin{array}{l}\text { 1. PUBLIC ATION OR REPORT NO. } \\
\text { 77-1401 }\end{array}$ & $\begin{array}{l}\text { 2. Gov't Accession } \\
\text { No. }\end{array}$ & 3. Recipient's Accession No. \\
\hline \multirow{2}{*}{\multicolumn{3}{|c|}{$\begin{array}{l}\text { 4. TITIE AND SUHTITLE } \\
\text { Processing and Characterization of NBS Standard Polyethylene } \\
\text { for Use as a Negative Control Material }\end{array}$}} & $\begin{array}{l}\text { 5. Publication Date } \\
\text { January } 1978\end{array}$ \\
\hline & & & 6. Performing Organization Code \\
\hline \multicolumn{3}{|c|}{$\begin{array}{l}\text { 7. AUTHOR(S) } \\
\text { Anthony J. Bur }\end{array}$} & 8. Performing Organ. Report No. \\
\hline \multirow{2}{*}{\multicolumn{3}{|c|}{$\begin{array}{l}\text { 9. PERFORMING ORGANIZATION NAME AND ADDRESS } \\
\text { NATIONAL BUREAU OF STANDARDS } \\
\text { DEPARTMENT OF COMMERCE } \\
\text { WASHINGTON, D.C. } 20234\end{array}$}} & $\begin{array}{l}\text { 10. Project/Task/Work Unit No. } \\
3110118\end{array}$ \\
\hline & & & 11. Contract/Grant No. \\
\hline \multirow{2}{*}{\multicolumn{3}{|c|}{$\begin{array}{l}\text { 12. Sponsoring Organization Name and Complete Address (Street, City, State, ZIP) } \\
\text { Materials Science Toxicology Laboratories } \\
\text { College of Dentistry and College of Pharmacy } \\
\text { University of Tennessee Medical Units } \\
\text { Memphis, TN } 38163\end{array}$}} & $\begin{array}{l}\text { 13. Type of Report \& Period } \\
\text { Covered Final Report } \\
9 / 1 / 76-8 / 31 / 77\end{array}$ \\
\hline & & & 14. Sponsoring Agency (ode \\
\hline
\end{tabular}

15. SUPPI.EMENTARY NOTES

16. ARSTRACT (A 200 word or less factual summary of most significant information. If document includes a significant bibliography or literature survey, mention it here.)

This work was initiated in order to fulfill a need for a polymer which can serve as a negative control material for biocompatibility studies involving new polymer implant materials. Two large batches of well-characterized polyethylene resin are the sources of the candidate negative control material. The original polyethylene resin, in pellet form, was processed into sheets and rods and examined for surface contaminants and uniformity. Surface observations consisted of measurements of contact angle, attenuated total reflectance infra-red absorption and secondary ion mass spectroscopy (SIMS). Bulk measurements consisted of density, differential scanning calorimetry , and transmission infra-red spectroscopy. All of the measurements, except SIMS, indicated that the material was uniform and typically polyethylene with no macroscopic contamination. The SIMS measurement, which is a sensitive analytical tool for detecting low levels of elemental contamination, showed significant differences between the type, of contamination on the surfaces of the starting material and the type of contamination on the processed sheet and rod. The method of processing was also significant because the extruded rod showed much more contamination than did the compression molded sheet. The surfaces of the rod were found to contain metallic oxides and several other metals which were not present in the unprocessed polyethylene. It is concluded that close attention must be paid to the method of processing and that only a sensitive analytical tool such as SIMS can be used to detect surface contamination and the differences between these samples.

17. KEY WORDS (six to twelve entries; alphabetical order; capitalize only the first letter of the first key word unless a proper name; separated by semicolons) Biomaterials; negative control; polyethylene; processing sheets and rods; surface characterization; surface contamination.

18. AVAII.ABILITY

For Official Distribution. Do Not Release to NTIS

Order lirom Sup. of Doc., U.S. Government Printing Office Washington, 1).C. 20402, SDCat. No. C:13

X. Order from National Technical Information Service (NTIS) springfield, Virginia 22151

\begin{tabular}{|c|c|}
\hline $\begin{array}{l}\text { 19. SECURITY CLASS } \\
\text { (THIS REPURT) } \\
\text { UNCL ASSIFIED }\end{array}$ & $\begin{array}{l}\text { 21. NO. OF PAGES } \\
32\end{array}$ \\
\hline $\begin{array}{l}\text { 20. SHCURITY CLASS } \\
\text { (TIIS PAGE) } \\
\text { UNCLASSIFIED) }\end{array}$ & $\begin{array}{l}\text { 22. Price } \\
\$ 4.50\end{array}$ \\
\hline
\end{tabular}



